\title{
Fatigue monitoring of metals based on mechanical hysteresis, electromagnetic ultrasonic, electrical resistance and temperature measurements
}

\author{
Dietmar EIFLER*, Marek SMAGA* and Marcus KLEIN* \\ *Institute of Materials Science and Engineering, University of Kaiserslautern \\ P.B. 3049, 67653 Kaiserslautern, Germany \\ E-mail: Eifler@mv.uni-kl.de
}

Received 10 May 2016

\begin{abstract}
Alternatively to conventional stress-strain hysteresis measurements in this paper physically based materials data such as specimen temperature, electrical resistance, speed of sound or generator power are used to describe the cyclic deformation behavior of metals in the high cycle (HCF) and the very high cycle fatigue (VHCF) regime. The mentioned physical parameters depend in a characteristic manner on the load and cycle dependent microstructure of metals. The change in temperature is proportional to the dissipated energy due to cyclic plastic deformation, the electrical resistance and speed of sound in metals depend on the individual dislocation and defect structure. Amongst others the generator power of ultrasonic testing machines is influenced by the internal friction of the material and consequently from the microstructure of a fatigued material. In analogy to the plastic strain amplitude all these data can be used to describe the cyclic deformation behavior and to calculate $\mathrm{S}, \mathrm{N}$-curves. The materials investigated are taken from technical components such as power plants, high speed trains and automotive industry to demonstrate that the presented methods and physical parameters can be used to describe the cyclic deformation and fatigue behavior of different steels with different microstructures. Related to the regarded materials and fatigues states SEM and TEM investigations were used to identify microstructural details such as slip bands, micro cracks, crack initiation sites and typical dislocation structures as well as phase transformations.
\end{abstract}

Key words : Fatigue, Cyclic deformation behavior, Steels, Physical fatigue parameters, SEM, TEM

\section{Introduction}

Reliable fatigue life calculations of metallic materials require a systematic investigation of their cyclic deformation behavior and a comprehensive understanding of the fatigue mechanisms. The purpose of the present paper is to demonstrate that besides conventional stress-strain measurements (Morrow, 1965) parameters such as change in temperature, electrical resistance or speed of sound can be used alternatively to characterize the cyclic deformation and fatigue behavior of steels. Stress-controlled fatigue tests were carried out with frequencies of 0.01 and $5 \mathrm{~Hz}$ on servo-hydraulic test systems. Additionally fatigue tests at $20 \mathrm{kHz}$ were realized with an ultrasonic test system. In most cases, the plastic strain amplitude is used to characterize the cyclic deformation behavior of metals (Klesnil et al., 1980; Mughrabi, 2002). For certain material conditions e.g. high strength steels the plastic strain amplitudes cannot be used for reliable life time prediction or at very high test frequencies in the VHCF regime the measurement of the plastic strain amplitude is not possible at all (Murakami, 1999; Murakami, 2002; Wang, 2002; Bathias, 2006). Therefore in the present investigation physical phenomena such as the cycle and load dependent change of the deformation-induced temperature $\Delta \mathrm{T}$, the change in electrical resistance $\Delta \mathrm{R}$ as well as the change of the speed of sound were used for a detailed characterization of the cyclic deformation behavior of metals. The electrical resistance depends on the resistivity, which is strongly influenced by the defect structure and defect density of each individual material (Kramer et al., 2014; Starke et al., 2009). At temperatures around ambient temperature (AT), plastic deformation of metastable austenitic steels often results in a phase transformation from paramagnetic austenite into ferromagnetic $\alpha^{\prime}$-martensite 
(Altpeter et al., 2012; Bayerlein et al., 1989; Lo et al., 2009; Mughrabi et al., 1997; Sorich et al., 2015). The cyclic deformation behavior of metastable austenitic steels is predominantly influenced by changes in dislocation structure and phase transformations. In the case of metastable austenitic steels electromagnetic acoustic transducers (EMAT) can be used for the early detection of fatigue and to describe the cyclic deformation behavior on the basis of time of flight of sound. The measured physical data were interpreted by SEM and TEM investigations.

\section{Materials and experimental setup}

\subsection{Materials}

The investigated materials are the Nb-stabilized metastable austenitic stainless steel AISI 347 (Fig. 1(a)) which is used for pipes in nuclear plants, the ferritic-perlitic steel SAE 1065 (Fig. 1(b)) which is used for rail way wheels and the quenched and tempered steel SAE 4140 which is used in automotive industry. These different steels and heat treatment conditions were chosen to show that the proposed physical quantities work for different alloys and different microstructures. The calculation of the austenite stability parameters of the steel AISI 347 results in a metastable state of the test material at ambient temperature. That means at a sufficient plastic deformation at ambient temperature an austenite-martensite-transformation can be expected during cyclic loading.

(a)

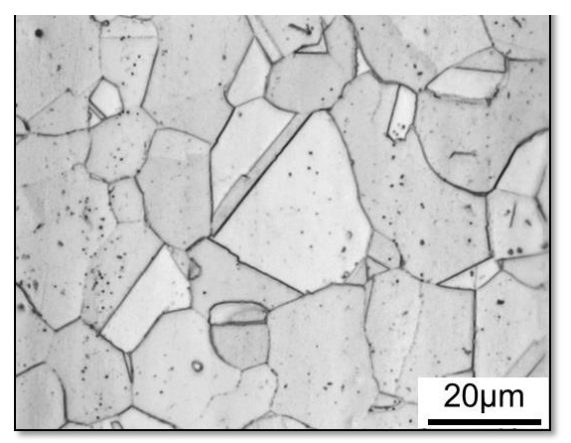

(b)

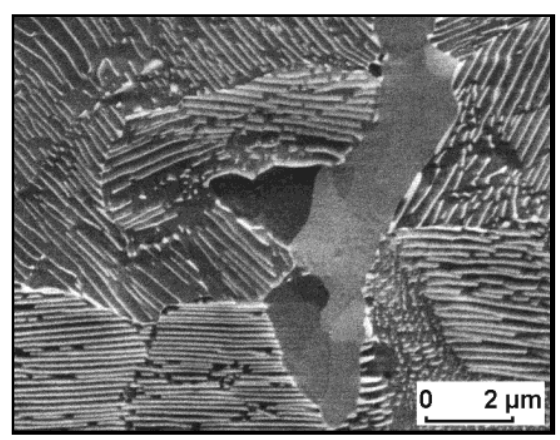

(c)

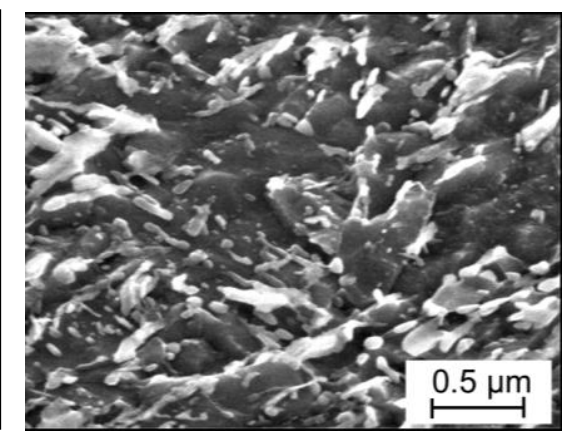

Fig. 1 SEM micrographs of AISI 347 in a solution annealed state (a), ferritic-perlitic SAE 1065 (b) and quenched and tempered SAE 4140 (c).

\subsection{Experimental setup}

Axial single step tests (SST) and load increase tests (LIT) were performed on a $250 \mathrm{kN}$ MTS servo-hydraulic testing system of the type 810 using a triangular load-time function in the LCF range under total strain control at a frequency $f=0.01 \mathrm{~Hz}$ and in the $\mathrm{HCF}$ range under stress control at $\mathrm{f}=5 \mathrm{~Hz}$. In both cases a load ratio of $\mathrm{R}=-1$ was used. The measurement set up is shown in Fig. 2. For electrical resistance measurements a direct-current power supply was fixed at both specimen shafts and the change in electrical resistance $\Delta \mathrm{R}$ was measured with two wires fixed at the transitions between the gauge length and the shafts. The change in deformation induced specimen temperature $\Delta \mathrm{T}$ was measured with three thermocouples mounted at the specimens. The three thermocouples were fixed at the specimens surface (Fig. 2). The cross-sections at the temperature measuring points $\mathrm{T}_{2}$ and $\mathrm{T}_{3}$ are significantly larger compared to $\mathrm{T}_{1}$. Thus, the temperature difference $\Delta \mathrm{T}=\mathrm{T}_{1}-0.5\left(\mathrm{~T}_{2}+\mathrm{T}_{3}\right)$ is only caused by plastic deformation in the gauge length. Thermocouple 4 was used to measure the temperature in the specimen chamber. Additionally electromagnetic non-destructive test methods with an EMAT-system, a magnetic sensor to detect the magnetic fraction and conventional strain-stress hysteresis measurements were performed. The electromagnetic acoustic transducer (EMAT) developed at the Fraunhofer Institute for Non-Destructive Testing (IZFP), Saarbrücken, Germany allows measurements on surfaces and components without coupling liquid also at elevated temperatures and is described in detail in Salzburger, 2009. EMATs generate ultrasonic waves by means of Lorentz-forces, magnetostriction or by magnetic forces. Because the investigated material is a paramagnetic austenitic steel, in the described experiments the ultrasonic waves were generated only by Lorentz-forces. Fig. 3 (a) shows the electromagnetically activated ultrasonic signal in an austenitic fatigue specimen. The analysis of the data has shown that the change in the time of flight (tof) and the change in the 
amplitude which are influenced by the cycle and load dependent microstructure of the material carry the highest potential for the characterization of the fatigue behavior. In this paper the mean value of the time of the flight signal tof $_{\text {mean }}$ (Fig. 3 (b)), was chosen to characterize the cyclic deformation behavior. The phase transformation from paramagnetic austenite to ferromagnetic $\alpha^{\prime}$-martensite was measured in-situ using a magnetic sensor FERITSCOPE® MP30E with an attached probe EGAB1.3 Fe. The measured magnetic fraction $(\xi)$ of this sensor is indicated in ferrite $\%$ (FE-\%).

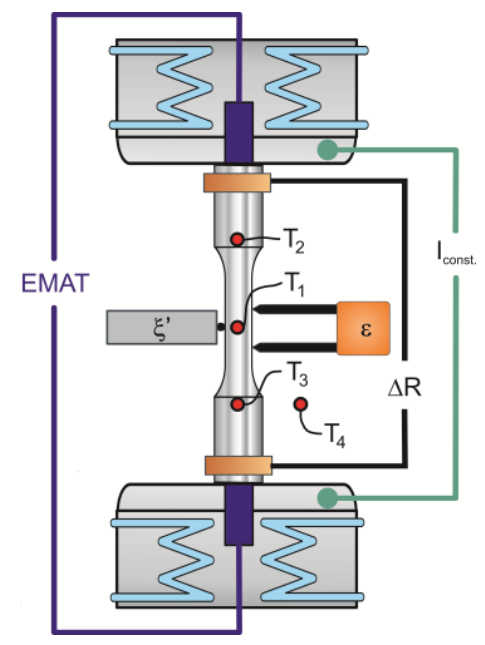

$(\sigma-\varepsilon)$ stress-strain

$(\Delta \mathrm{T})$ temperature

$(\Delta \mathrm{R})$ el. resistance

( $\xi$ magnetic fraction

EMAT: Electromagnetic

acoustic transducer

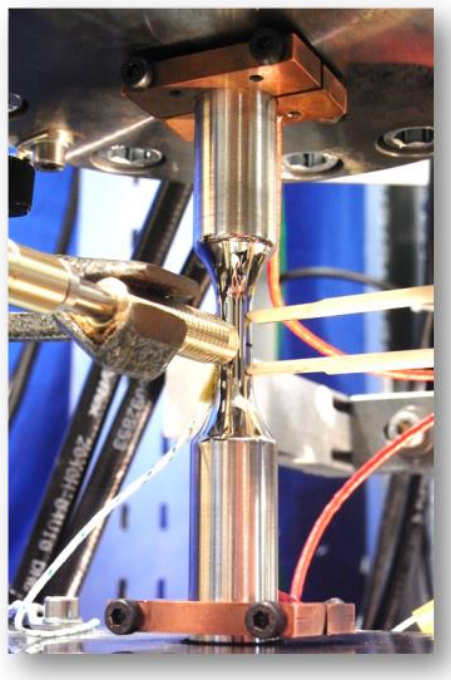

Fig. 2 Schematic and real illustration of the measurement setup with stress-strain-, temperature-, electrical resistanceand magnetic fraction-measurement as well as EMAT probes of the radially polarized shear wave type in the grips of a servo-hydraulic testing system for fatigue tests at ambient temperature together with an extensometer.

(a)

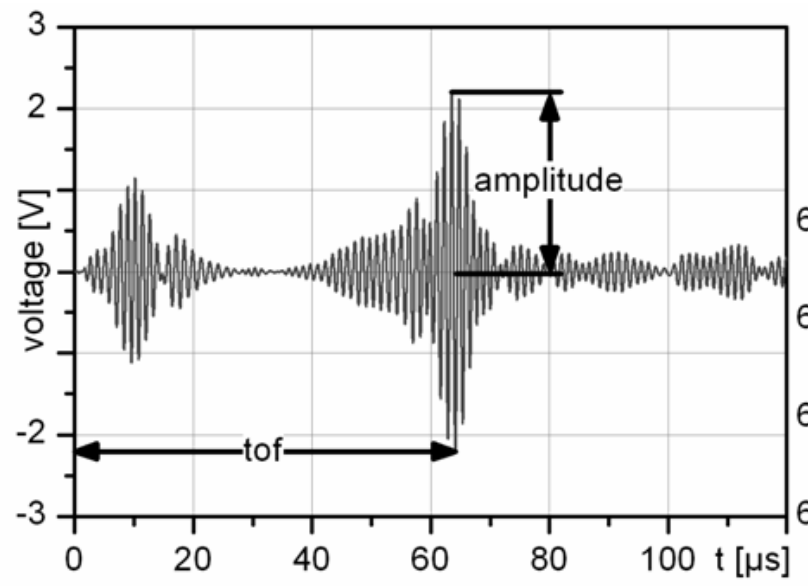

(b)

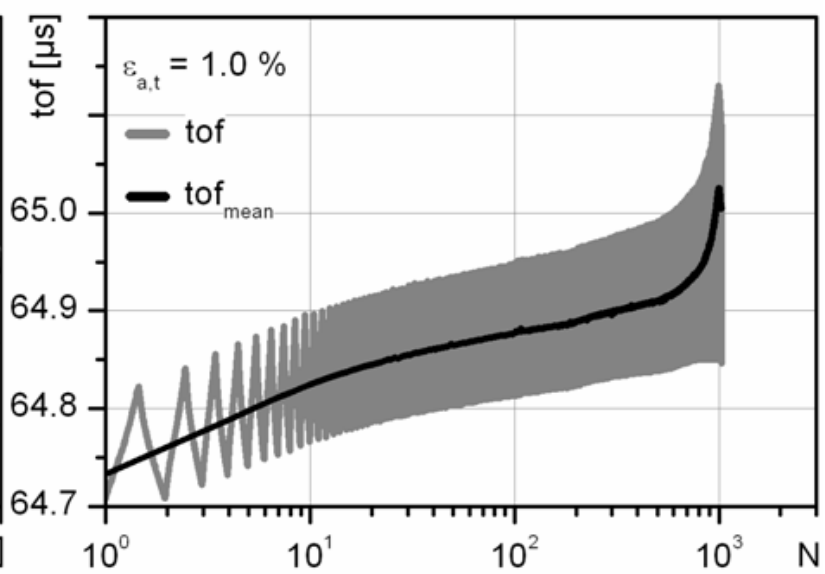

Fig. 3 Time of flight (tof) and ultra-sound-amplitude (a) and tof and mean value of tof per load cycle (tof $f_{\text {mean }}$ ) during a single step test at ambient temperature (b).

The specimen design for the fatigue tests is shown in Fig. 4. The specimen of type (a) was used in the servo-hydraulic test system and type (b) was used for the ultrasonic fatigue tests. In the design process of the VHCF specimen finite element methods (FEM) were used to achieve an eigenfrequency of $20 \mathrm{kHz}$. In addition to the FEM analysis strain gauge measurements and non-contact strain evaluations with a 3D laser scanning vibrometer were performed to validate the calculated stress amplitudes. The specimen design is well suited to realize displacement amplitudes between 7 and $55 \mu \mathrm{m}$ and stress amplitudes between 80 and $750 \mathrm{MPa}$ at a test frequency of $20 \mathrm{kHz}$. 
(a)

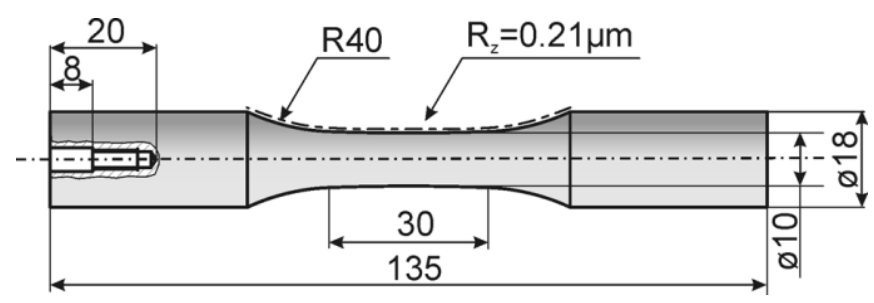

(b)

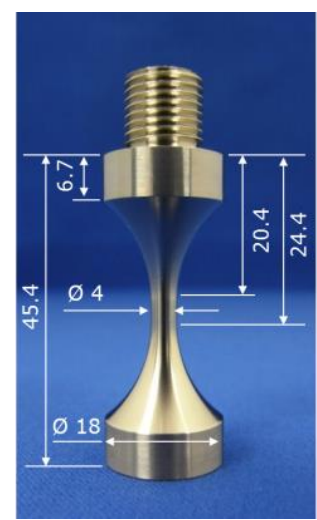

Fig. 4 Shape and dimensions in $\mathrm{mm}$ of the fatigue specimens for servo-hydraulic (a) and ultrasonic (b) test systems.

\section{Results and discussion}

\subsection{Cyclic deformation behavior of metastable austenite at ambient temperature with deformation induced $\alpha^{\prime}$-martensite formation}

The cyclic deformation behavior of the investigated austenite is predominantly determined by the deformation induced austenite-martensite transformation and can be described by the development of the stress amplitude $\sigma_{\mathrm{a}}$ and

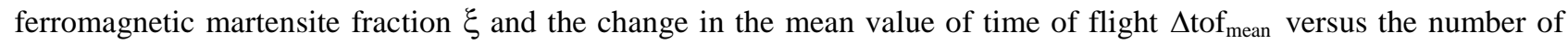
cycles $\mathrm{N}$ for fatigue tests at ambient temperature (Fig. 5). After a load dependent number of cycles $\mathrm{N}$, the formation of $\alpha^{\prime}$-martensite starts and increases continuously with increasing number of cycles until specimen failure. The $\sigma_{\mathrm{a}}$, $\mathrm{N}$-curves illustrate the corresponding cyclic hardening processes, which can lead to a maximum stress amplitude in the range of the tensile strength $\mathrm{R}_{\mathrm{UTS}}=569 \mathrm{MPa}$ of the solution-annealed austenite. The ongoing fatigue process is also visualized in the SEM investigations on the right side of Fig.5 which shows slip bands (thin arrows) at N=10 and 100 and in a later fatigue state at $\mathrm{N}=400$ cycles micro cracks (wide arrows) at the specimen surface. TEM investigations were performed at ambient temperature in defined fatigue states (Fig. 6). At $\mathrm{N}=100$ an increase of the dislocation density and the formation of dislocation cells were observed. Continuing cycling until $\mathrm{N}=928$, results in well defined dislocation cells and transformation induced $\alpha^{\prime}$-martensite. The dark field mode allows the direct observation of the crystallites and hence, it is possible to visualize the transformation induced $\alpha^{\prime}$ - martensite.
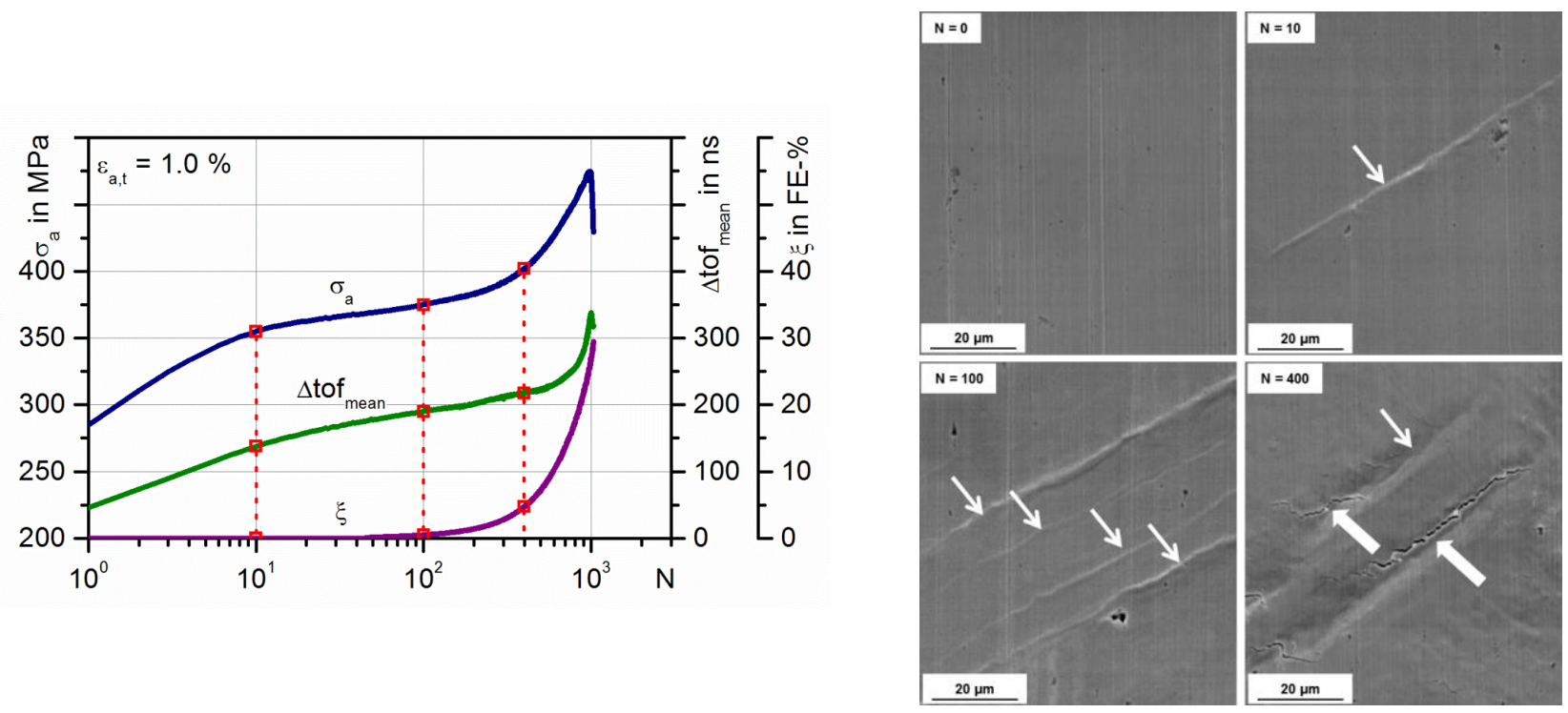

Fig. 5 Stress amplitude $\sigma_{\mathrm{a}}$, mean value of time of flight $\Delta$ tof $_{\text {mean }}$ and ferromagnetic martensite fraction $\xi$ combined with slip bands (thin arrows) and micro cracks (wide arrows) at the specimen surface of AISI 347 as function of $\mathrm{N}$ for $\mathrm{f}=0.01 \mathrm{~Hz}$ at $\mathrm{AT}$. 
Besides the deformation-induced $\alpha^{\prime}$-martensite there are additional microstructural effects influencing $\Delta$ tof mean $_{\text {density }}$ and arrangement of dislocations and fatigue induced changes of the surface topography in terms of slip bands and micro cracks as well as makro cracks. Due to the increase of the dislocation density, the formation of deformation-induced $\alpha^{\prime}$-martensite, the development of intrusions and extrusions at the specimen surface and finally the formation of micro and macro cracks a continuous increase of the mean value of time of flight $\Delta$ tof mean $_{\text {from the }}$ first cycle until specimen failure was observed at ambient temperature. Additionally to the described microstructural changes, residual stresses can influence the ultrasonic velocity and attenuation (Sorich et al., 2015).
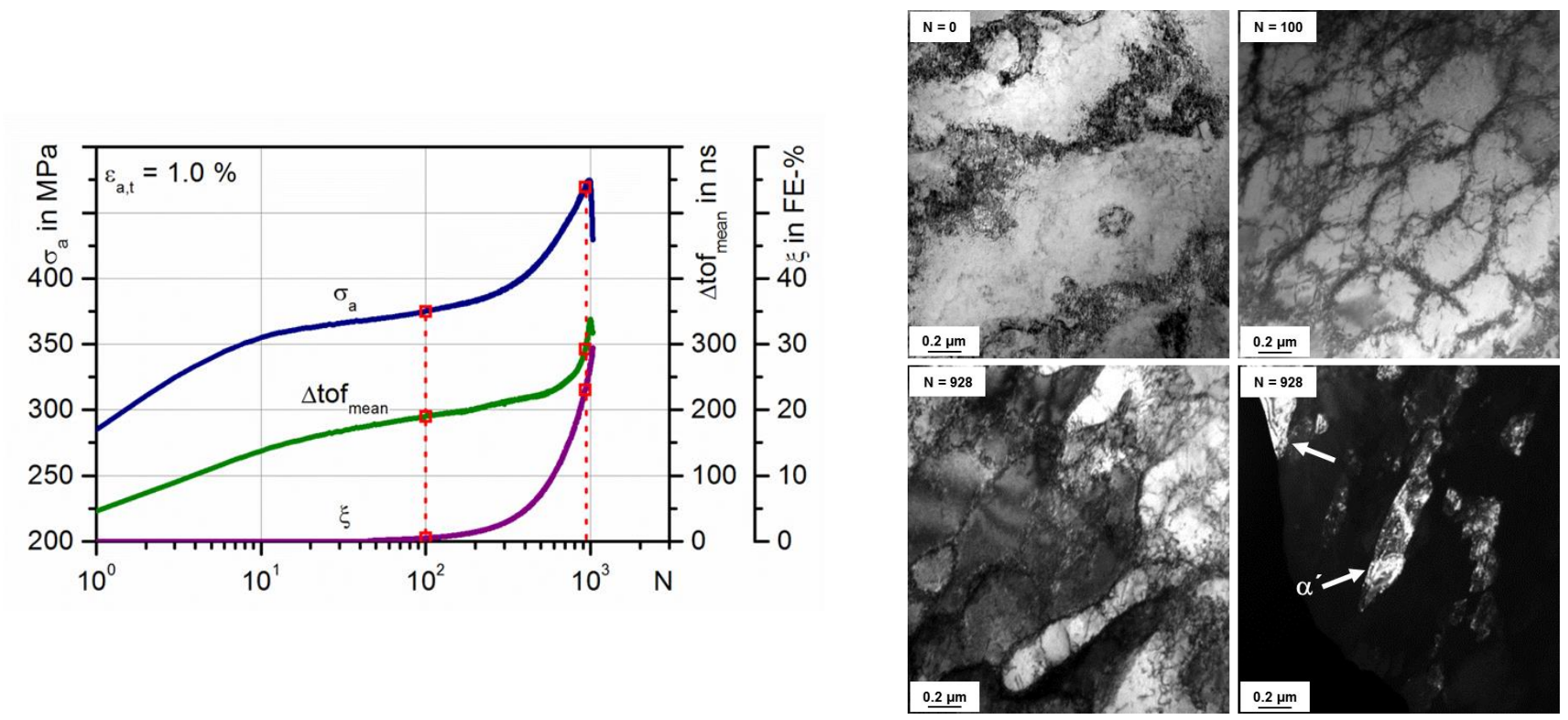

Fig. 6 Stress amplitude $\sigma_{\mathrm{a}}$, mean value of time of flight $\Delta$ tof $_{\text {mean }}$ and martensite fraction $\xi$ combined with dislocation arrangement of AISI 347 at $\mathrm{N}=0,100$ and 928 cycles for $\mathrm{f}=0.01 \mathrm{~Hz}$ at AT; dark field mode shows $\alpha^{\prime}$-martensite.

\subsection{Cyclic deformation behavior at $300{ }^{\circ} \mathrm{C}$}

Figure 7 shows the development of the stress amplitude $\sigma_{\mathrm{a}}$ (Fig. 7(a)) and the change in the mean value of time of flight $\Delta$ tof $f_{\text {mean }}$ (Fig. 7(b)) versus the number of cycles $\mathrm{N}$ for fatigue tests at $300{ }^{\circ} \mathrm{C}$ (Sorich et al., 2014). The cyclic deformation behavior of the investigated metastable austenite at this temperature is characterized by initial cyclic hardening, followed by cyclic softening before the final stress amplitude drop, associated with the propagation of a macro crack. At $300{ }^{\circ} \mathrm{C}$ in the LCF-range the austenite is stable and no martensite formation occurs and compared to ambient temperature the stress amplitude is significantly lower. In the $\Delta$ tof $_{\text {mean }}$, N-curves generally three sections over fatigue life were observed. In the first section $\Delta$ tof $_{\text {mean }}$ shows a similar slope as $\sigma_{\mathrm{a}}$ and tests at ambient temperature reveal an initial increase caused by dislocation hardening. The second section is characterized by a decrease of $\Delta$ tof ${ }_{\text {mean }}$ due to cyclic softening. The third one shows a secondary increase of $\Delta$ to $f_{\text {mean }}$, which is mainly affected by the development of slip bands at the specimen surface and finally the inititation and propagation of fatigue cracks (comp. Fig. 5). Figure 8(a) shows a EBSD-micrograph of a specimen at $\mathrm{N}=0.9 \mathrm{~N}_{\mathrm{f}}$ loaded with $\varepsilon_{\mathrm{a}, \mathrm{t}}=1 \%$ at $300{ }^{\circ} \mathrm{C}$. Obviously no $\alpha^{\prime}$-martensite formation occurs at these loading conditions. Well-defined dislocation cells and dislocation pile-ups along grain boundaries are observed in Fig. 8(b). 
(a)

\section{Stress amplitude}

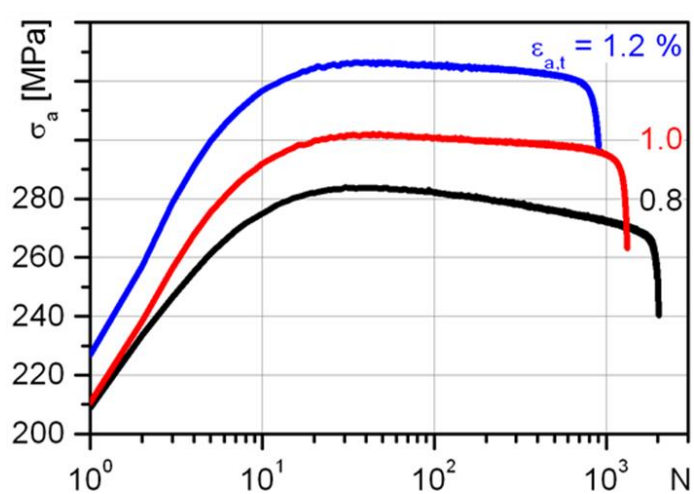

(b)

Mean value of time of flight

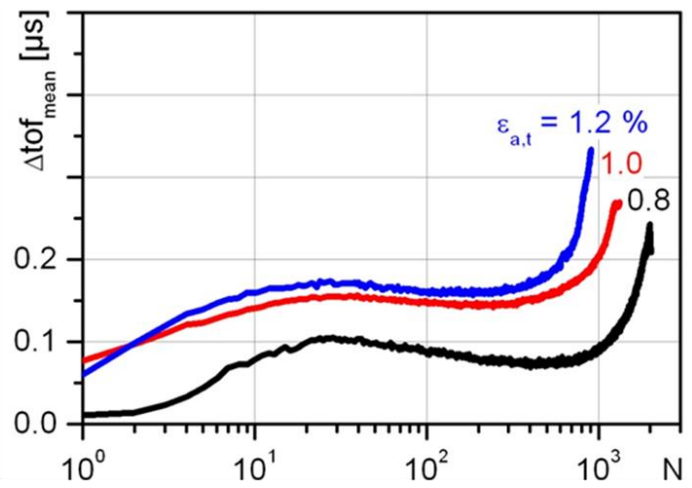

Fig. 7 Stress amplitude $\sigma_{\mathrm{a}}$ (a) and change in $\Delta$ tof $f_{\text {mean }}$ (b) vs. number of cycles $\mathrm{N}$ of AISI 347 at $\mathrm{T}=300{ }^{\circ} \mathrm{C}$.

(a)

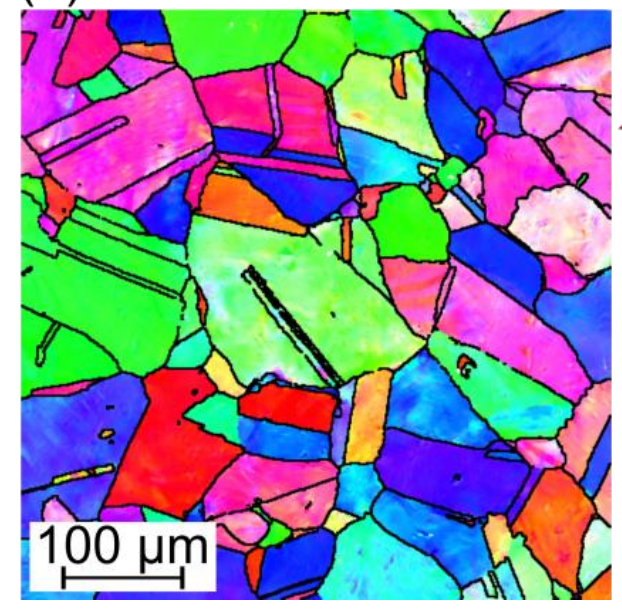

(b)

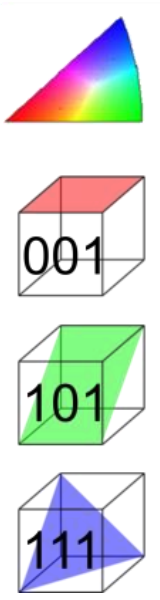

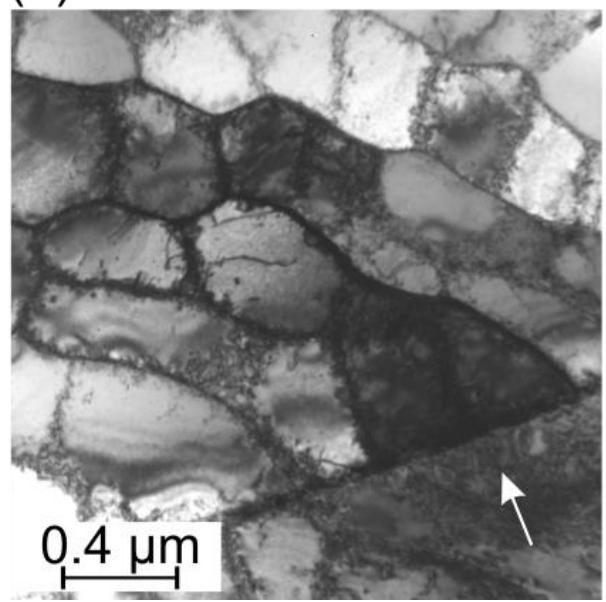

Fig. 8 EBSD- (a) and TEM- (b) micrograph of AISI 347 at $\mathrm{N}=0.9 \mathrm{~N}_{\mathrm{f}}$ of a specimen loaded with $\varepsilon_{\mathrm{a}, \mathrm{t}}=1 \%$ at $300{ }^{\circ} \mathrm{C}$.

\subsection{Temperature and resistance measurements to characterize the cyclic deformation behavior}

To demonstrate the universal applicability of temperature and resistance measurements to characterize the cyclic deformation behavior as a technical example in section 3.3 specimens taken from an original rail way wheel of a high speed train are investigated. In Fig. 9(a) the development of $\varepsilon_{a, p}, \Delta T$ and $\Delta R$ versus the number of cycles $N$ is shown as sets of cyclic 'deformation' curves at $\sigma_{\mathrm{a}}=500 \mathrm{MPa}$. For each measured value the upper and lower limiting cyclic 'deformation' curves are plotted. The quasi-elastic incubation interval is followed by cyclic softening until about $5 \% \mathrm{~N}_{\mathrm{f}}$ and subsequent cyclic hardening until macro crack growth. The change of specimen temperature $\Delta \mathrm{T}$, which is proportional to the dissipated energy due to cyclic plastic deformation, and the change of the electrical resistance $\Delta \mathrm{R}$ correspond very well to the plastic strain amplitude $\varepsilon_{\mathrm{a}, \mathrm{p}}$ as shown in the linear relation between the three parameters in Fig. 9(b). The numbers 1 and 4 indicate different positions in the cross section of the wheel. At position 1 the ferrite fraction is 1.5 area-\% and at position 41.8 area- $\%$. Consequently due to the higher plastic deformation capability the plastic strain amplitude and change in temperature are higher at position 4 . Obviously, the different measuring techniques show a strong interrelation with the actual fatigue process and result in similar cyclic 'deformation' curves (Starke et al., 2009). 
(a)

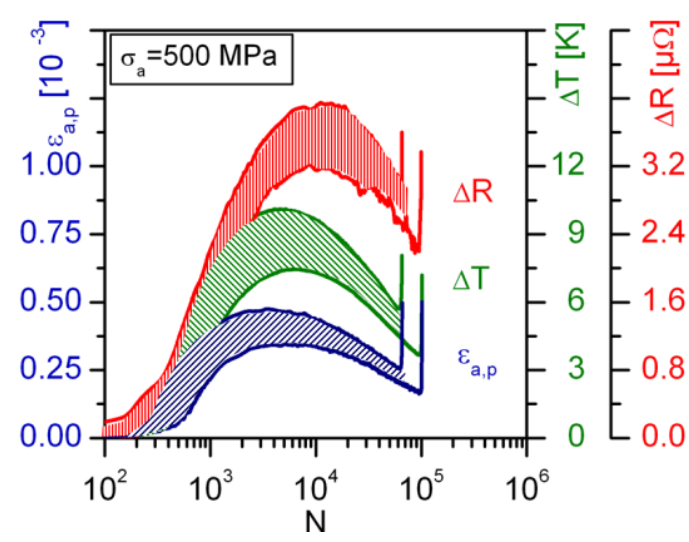

(b)

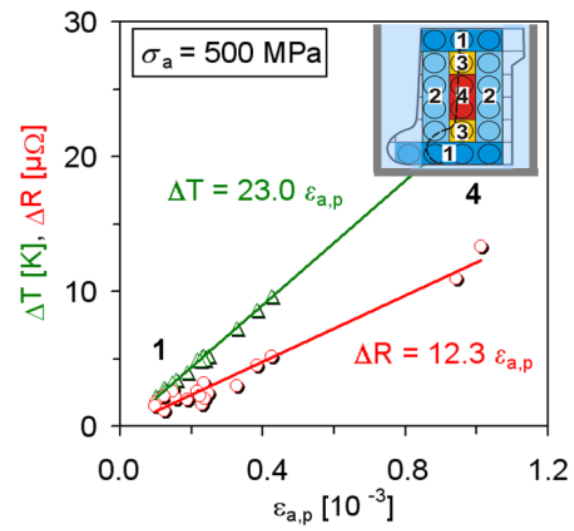

Fig. 9 Cyclic deformation, temperature and resistance curves (a), linear relation between $\varepsilon_{a, p}, \Delta \mathrm{T}$ and $\Delta \mathrm{R}$ (b) of ferritic-perlitic rail way wheel steel SAE 1065.

In modified Morrow and Manson-Coffin curves, the plastic strain amplitude can be substituted by temperature and resistance data. Equivalent to cyclic stress-strain (CSS) curves, cyclic stress-temperature (CST) and cyclic stress-resistance (CSR) curves can be approximated by a generalized power law according to Morrow:

$$
\sigma_{a}=K^{\prime} \cdot\left(\varepsilon_{a, p}\right)^{n^{\prime}} \rightarrow \sigma_{a}=a(M) \cdot(M(N))^{b(M)}
$$

Equation (1) describes the relationship between the stress amplitude $\sigma_{\mathrm{a}}$ and the measured values $\mathrm{M}(\mathrm{N})=\varepsilon_{\mathrm{a}, \mathrm{p}}, \Delta \mathrm{T}, \Delta \mathrm{R}$ or $\Delta \mathrm{R}_{\text {load-free }}$ at a defined number of cycles. In this case $\mathrm{a}(\mathrm{M})$ corresponds to the cyclic hardening coefficient and $\mathrm{b}(\mathrm{M})$ the cyclic hardening exponent.

The power law according to Manson-Coffin can be expressed in a similar way:

$$
\varepsilon_{a, p}=\varepsilon_{B}^{\prime} \cdot\left(2 N_{f}\right)^{c} \rightarrow M(N)=c(M) \cdot\left(2 N_{f}\right)^{d(M)}
$$

with the ductility coefficient $\mathrm{c}(\mathrm{M})$ and the ductility exponent $\mathrm{d}(\mathrm{M})$.

$\mathrm{M}(\mathrm{N})$ in Equation (1) can be substituted by Equation (2), leading to a generalized Basquin law:

$$
\sigma_{a}=\sigma_{f}^{\prime} \cdot\left(2 N_{f}\right)^{b} \rightarrow \sigma_{a}=a(M) \cdot\left[c(M) \cdot\left(2 N_{f}\right)^{\mathrm{d}(\mathrm{M})}\right]^{b(M)}
$$

The material parameters $a(M), b(M), c(M)$ and $d(M)$ are determined by plastic strain, temperature and electrical resistance measurements, respectively.

According to the Manson-Coffin law the $\varepsilon_{\mathrm{a}, \mathrm{p}}, \Delta \mathrm{T}$ and $\Delta \mathrm{R}$ data at $\mathrm{N}_{\mathrm{f}} / 2$ are plotted versus the number of cycles to failure $\mathrm{N}_{\mathrm{f}}$ in Fig. 10 for $\sigma_{\mathrm{a}}=500 \mathrm{MPa}$. The data points represent 19 different specimen positions in the cross-section of a railway wheel (comp. Fig. 9 (b)) for the same stress amplitude. The maximum values of the ferrite fraction and the cementite lamellae spacing in the cross-section center (postion 4) lead to maximum plastic strain, temperature and resistance values combined with a minimum lifetime of about $\mathrm{N}_{\mathrm{f}}=2.2 \cdot 10^{4}$ cycles. Decreasing plastic deformation towards the wheel surface (position 1) leads to substantially longer lifetimes up to $\mathrm{N}_{\mathrm{f}}=4.0 \cdot 10^{5}$ cycles. The differences 
in the $\varepsilon_{\mathrm{a}, \mathrm{p}}, \Delta \mathrm{T}$ and $\Delta \mathrm{R}$ values as well as in the number of cycles to failure for the same loading amplitude are caused by the small differences in the local microstructure in the cross section such as ferrite fraction and cementite lamellae spacing of the railway wheel due to locally different cooling rates of the wheel during the production process. Based on similar cyclic ductility exponents the Manson-Coffin curves for plastic strain, temperature and resistance measurements are nearly parallel. Consequently, the measuring techniques can be equivalently used for a qualified description of deformation-induced microstructural changes as well as for an assessment of the fatigue behavior and a lifetime prediction according to Manson-Coffin. The fatigue lifetime can be very precisely calculated on the basis of the physically based lifetime calculation concept PHYBAL which is described in detail in (Starke et al., 2009).

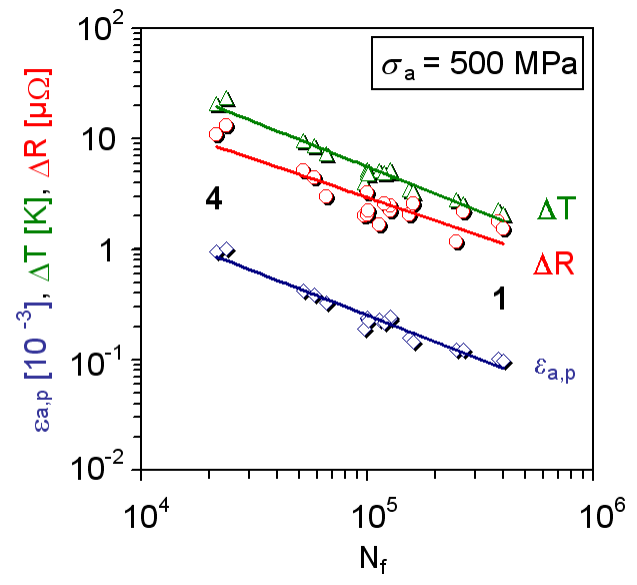

Fig. $10 \varepsilon_{a, p}{ }^{-}, \Delta \mathrm{T}$ - and $\Delta \mathrm{R}$ - Manson-Coffin curves of ferritic-perlitic SAE 1065.

The physical values $\varepsilon_{\mathrm{a}, \mathrm{p}}, \Delta \mathrm{T}$ and $\Delta \mathrm{R}$ can be equally used for a precise fatigue life calculation on the basis of Morrow and Basquin equations in a generalized formulation. The physical data were used in the fatigue life calculation method "PHYBAL" for the calculation of $\mathrm{S}, \mathrm{N}_{\mathrm{f}}$-curves. The "PHYBAL" concept allows reliable fatigue life calculations by using cyclic 'deformation' data of only one load increase test (LIT) and two single step tests (SST). Figure 11 shows a LIT of a quenched and tempered SAE 4140. The test started at a stress amplitude of $\sigma_{\mathrm{a}, \text { start }}=100 \mathrm{MPa}$ with a stepwise increase of $\Delta \sigma_{\mathrm{a}}=20 \mathrm{MPa}$ each $\Delta \mathrm{N}=9 \cdot 10^{3}$ cycles to estimate the endurance limit. In Fig. 11a), the stress amplitude $\sigma_{\mathrm{a}}$ and the change of the electrical resistance $\Delta \mathrm{R}$ are plotted versus the number of cycles $\mathrm{N}$. The transition from linear to exponential slope of the $\Delta \mathrm{R}, \mathrm{N}$-curve occurs at $\sigma_{\mathrm{a}, \mathrm{LIT}}=480 \mathrm{MPa}$ and failure at $\sigma_{\mathrm{a}}=680 \mathrm{MPa}$. The stress amplitude $\sigma_{\mathrm{a}, \mathrm{LIT}}$ can be used to estimate the endurance limit. In addition two SSTs were performed at the stress amplitudes 500 and 640 $\mathrm{MPa}$. In Fig. 11b) the cyclic deformation curves of both SSTs are plotted. The $\Delta \mathrm{R}, \mathrm{N}$-curves are characterised by continuous cyclic softening until failure what is typical for quenched and tempered steels.

(a)

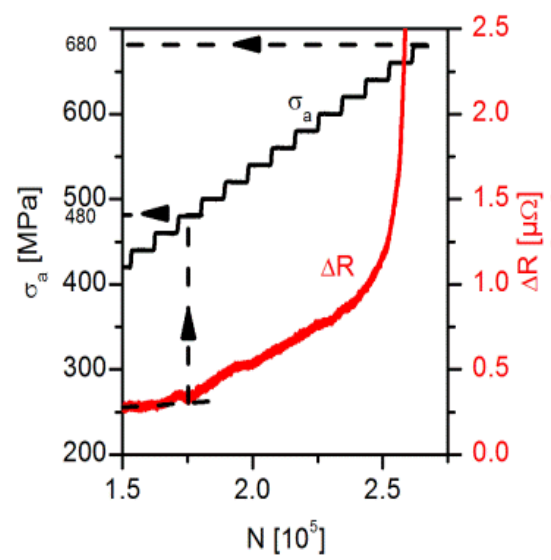

(b)

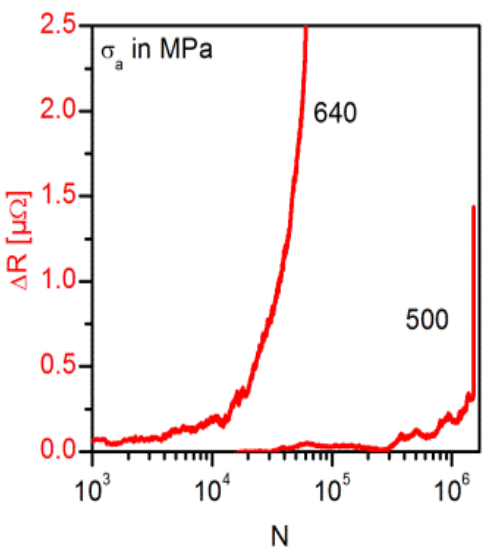

Fig. 11 Development of the electrical resistance in a load increase test (a) and in single step tests (b) of a quenched and tempered SAE 4140. 
Figure 12 proves that the experimentally determined $S, N_{f}$-curve based on 23 single step tests $(O)$ and the $S, N_{f}$-curves calculated on the basis of the plastic strain amplitude, the change of the temperature and electrical resistance of three experiments, one load increase test and two single step tests, agree very good.

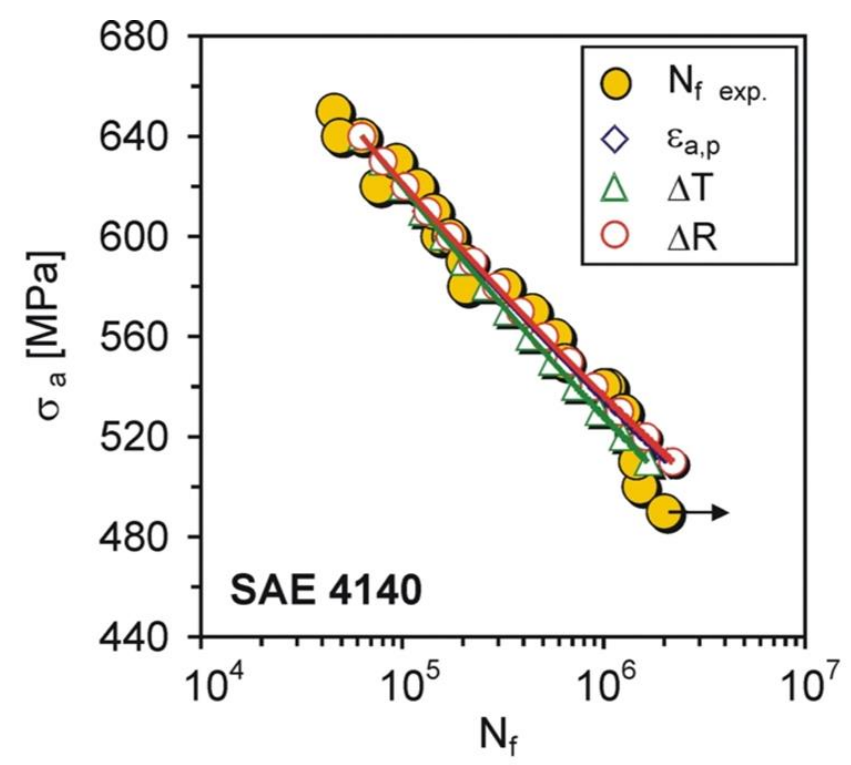

Fig. $12 \mathrm{~S}, \mathrm{~N}_{\mathrm{f}}$-curves calculated on the basis of $\varepsilon_{\mathrm{a}, \mathrm{p}}(\diamond), \Delta \mathrm{T}(\Delta)$ and $\Delta \mathrm{R}(\mathrm{O})$ from one LIT and two SSTs.

The physical parameters described above can also be used to characterize the fatigue behavior in the very high cycle fatigue regime (Koster et al., 2011, 2012). The ultrasonic fatigue tests were performed with the in-house-developed test system "UltraFAST-WKK-Kaiserslautern" (UFK) which is described in detail with all sensors used in the VHCF experiments in Heinz et al., 2011. At first preliminary load increase tests (LIT) were performed to identify the stress amplitudes which lead to defined changes of the physical test parameters in the ferritic-perlitic SAE 1065 also under VHCF loading conditions (Fig. 13). The SEM micrographs in Fig. 14 prove that the distinct temperature, power as well as energy increase at $4.07 \cdot 10^{7}$ is closely related to the formation of persistent slip bands (thin arrow) as well as intrusions, extrusions and micro cracks (wide arrow) at the specimen surface, emanating from phase boundaries between ferrite and cementite or grain boundaries between ferrite and pearlite. The formation of the slip bands seems to be initiated by the local differences of the elastic properties in this case between ferrite and cementite. This example clearly shows that physical data like temperature, power and energy can be used to indicate very local plastic deformation processes also at the very low loading amplitudes in the very high cycle fatigue regime.

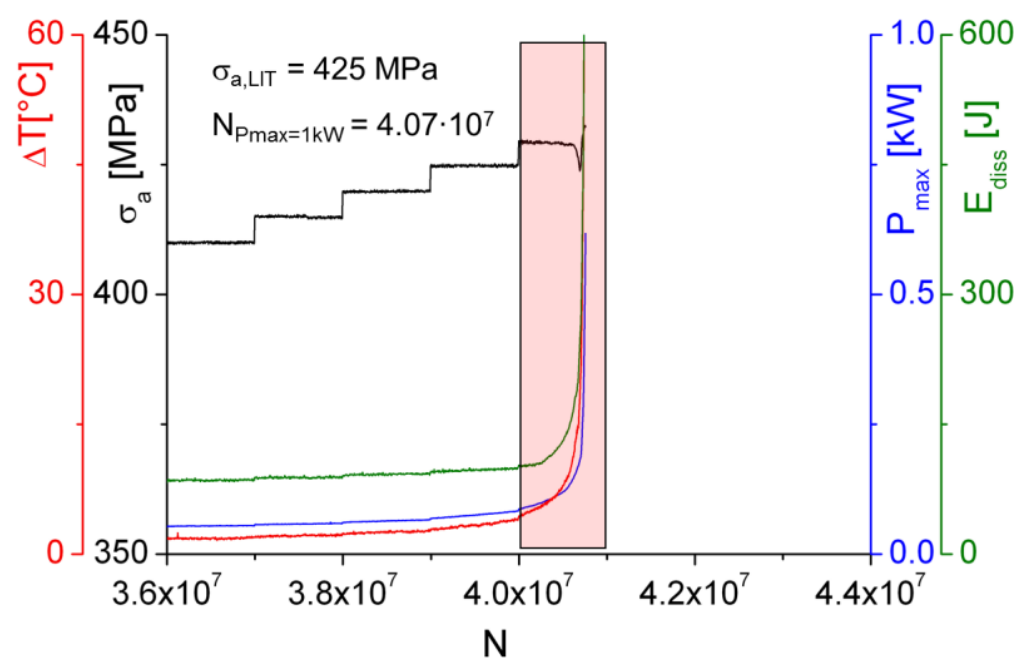

Fig. 13 Process parameters $\Delta \mathrm{T}, \mathrm{P}$ and $\mathrm{E}$ in a VHCF load increase test with ferritic-perlitic SAE 1065. 


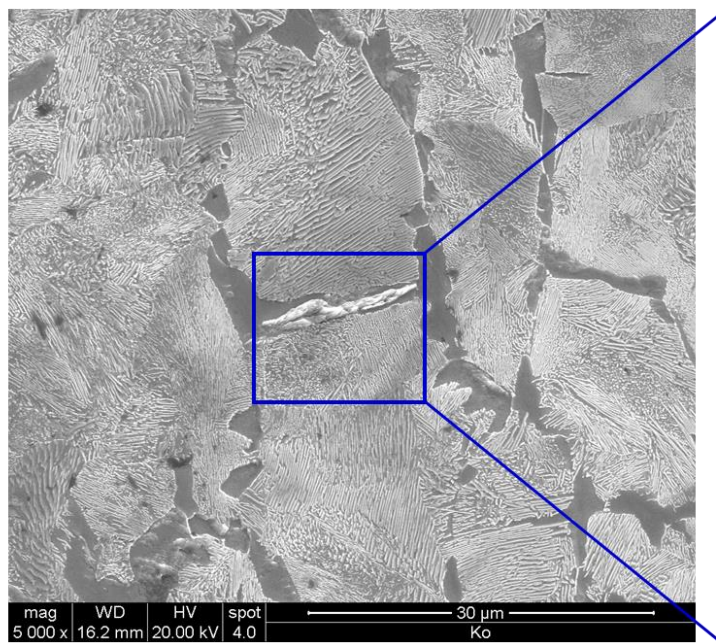

In- / Extrusion

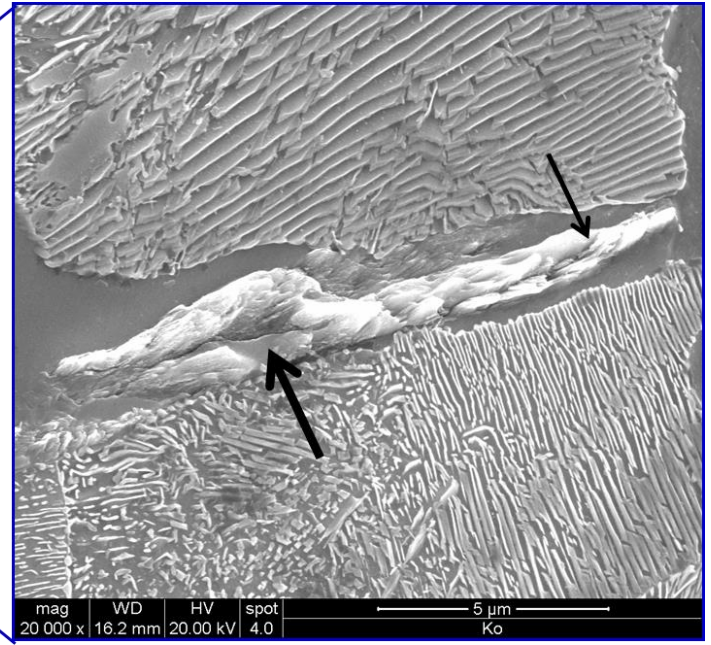

In- / Extrusion

Fig. 14 Slip band formation (small arrow) and micro crack (wide arrow) in the ferrite of ferritic-perlitic SAE 1065 in a VHCF load increase test after $4.07 \cdot 10^{7}$ cycles.

\section{Conclusions}

Additionally to conventional stress-strain-hysteresis measurements continuous in-situ measurements with electromagnetic acoustic transducers (EMAT) can be used to characterize the cyclic deformation behavior of the metastable austenitic steel AISI 347 at ambient and elevated temperatures. A very high sensitivity concerning the microstructure dependent cyclic deformation behavior could be proved for the measuring quantity time of flight of the ultrasound. In analogy to stress-strain-hysteresis the tof, $\varepsilon_{\mathrm{t}}$-hysteresis provides information about the cyclic hardening and/or softening processes as well as micro and macro crack initiation. With TEM, EBSD, SEM and FERITSCOPE ${ }^{\circledR}$ investigations it could be shown that the changes in the measuring quantity $\Delta$ tof $f_{\text {mean }}$ are correlated with the formation of $\alpha^{\prime}$-martensite (only at AT), changes of the dislocation density and arrangement as well as changes of the topography of the specimens. The fatigue behavior of the ferritic-perlitic railway wheel SAE 1065 steel is strongly influenced by the local microstructure in the cross section. The measured plastic strain amplitudes, temperature and electrical resistance are based on physical processes and represent the actual fatigue state. Between the plastic strain amplitude, the change of the temperature and the change of the electrical resistance a linear relation exists. These data can also be used to characterize fatigue processes in the VHCF regime. Due to their independence of a gauge length, temperature and electrical resistance measurements can be applied also on technical components. On the basis of modified Morrow and Manson-Coffin curves as well as a generalized Basquin equation the lifetime can be reliably calculated. A comparison of experimental with calculated S, N- curves based on plastic strain, temperature and resistance data reveal a very good accordance. This underlines that the physically based deformation data can be used to describe fatigue phenomena.

\section{Acknowledgement}

The authors thank the Ministry of Economy and Technology (BMWi), Germany as well as the German Research Foundation (DFG) for the financial support within the SFB 926 "Microscale Morphology of Component Surfaces". The EMAT probes were developed at the Fraunhofer Institute for Non-Destructive Testing (IZFP), Saarbrücken, Germany. The TEM investigations were performed at the Institute for Surface and Thin Film Analysis (IFOS), Kaiserslautern, Germany. 


\section{References}

Altpeter, I., Dobmann, G., Boller, C., Smaga, M., Sorich, A. and Eifler, D., Early detection of damage in thermo-cyclically loaded austenitic materials, Electromagnetic Nondestructive Evaluation XV, IOS Press 36 (2012), pp. 130-139.

Bathias, C., Piezoelectrical fatigue testing machines and devices, Int. J. Fatigue 28 (2006), pp. 1438-1445.

Bayerlein, M., Christ, H.J. and Mughrabi, H., „Plasticity-induced martensitic-transformation during cyclic deformation of AISI-304L stainless steel“", Mat. Sci. Eng. $A$ Vol. 114, (1989), pp. 11-16.

Heinz S., Wagner G. and Eifler, D., Innovative piezoelectrical testing facility for fatigue experiments in the VHCF regime, Proceedings of the Fifth International Conference on Very High Cycle Fatigue (2011), pp. 479-484.

Koster, M., Nutz, H., Freeden, W. and Eifler, D., Measuring techniques for the very high cycle fatigue behaviour of high strength steel at ultrasonic frequencies, International Journal of Materials Research, Volume 103 (2012), pp. 105-112.

Koster, M., Wagner, G. and Eifler, D., Ultrasonic Fatigue of the Railway Steel R7. In: Fifth International Conference in High Cycle Fatigue (VHCF5), Berger, C.; Christ, H.-J. (Hrsg.), DVM Verlag, Berlin, (2011), pp.147-152.

Kramer, H. S., Starke, P., Klein, M. and Eifler, D., Cyclic Hardness Test PHYBALCHT - short-time procedure to evaluate fatigue properties of metallic materials, Int. J. Fatigue 63 (2014), pp. 78-84.

Klesnil M., Lukas P.; Fatigue of Metallic Materials, Elsevier, Amsterdam, 1980).

Lo, K.H., Shek, C.H. and Lai, J.K.L., "Recent developments in stainless steels”, Mater. Sci. Eng. R Vol. 65, (2009), pp. 39-104.

Morrow J., Cyclic plastic strain energy and fatigue of metals, ASTM STP 378 Internal Friction, Damping, and Cyclic Plasticity, (1965), pp. 45-87.

Mughrabi, H. and Christ, H.J., "Cyclic deformation and fatigue of selected ferritic and austenitic steels: specific aspects”, ISIJ International Vol. 37, (1997), pp. 1154-1169.

Mughrabi H., On 'multi-stage' fatigue life diagrams and the relevant life-controlling mechanisms in ultrahigh-cycle fatigue, Fatigue Fract Eng M 25 (2002), pp. 755-764.

Murakami Y, Nomoto T and Ueda T., Factors influencing the mechanism of superlong fatigue failure in steels, Fatigue Fract Eng Mater Struct (1999), pp. 581-90.

Murakami Y, Yokoyama NN and Nagata J., Mechanism of fatigue failure in ultralong life regime, Fatigue Fract Eng Mater Struct, 25, (2002). pp. 735-46.

Sorich, A., Smaga, M. and Eifler, D., Influence of cyclic deformation induced phase transformation on the fatigue behavior of the austenitic steel X6CrNiNb1810, Advanced Materials Research, Vols. 891-892, (2014), pp. 1231-1236.

Sorich, A., Smaga, M. and Eifler, D., Fatigue Monitoring of Austenitic Steels with Electromagnetic Acoustic Transducers (EMATs), Mat. Per. and Char. 4, 263 (2015), pp. 263-274.

Stanzl-Tschegg SE., Fracture mechanisms and fracture mechanics at ultrasonic frequencies, Fatigue Fract. Eng. Mater. Struct. 22(7), (1999), pp. 567-579.

Starke P., Walther F. and Eifler, D., New fatigue life calculation method for quenched and tempered steel SAE 4140 , Mat. Sci. Eng. A 523,1-2 (2009), pp. 246-252.

Starke, P., Eifler, D., Fatigue assessment and fatigue life calculation of metals on the basis of mechanical hysteresis, temperature and resistance data, MP-Material Testing 51,5 (2009), pp. 261-268.

Wang QY, Bathias C, Kawagoshi N and Chen Q., Effect of inclusion on subsurface crack initiation and gigacycle fatigue strength, Int. J. Fatigue, 24 (2002), pp. 1269-1274. 